\title{
A cause of ulnar neuropathy in a baseball pitcher
}

\section{A case report}

\author{
EDWARD M. WOJTYS, MD, PATRICK A. SMITH, MD, AND FRED M. HANKIN, ${ }^{*}$ MD
}

From the Section of Orthopaedic Surgery, University of Michigan, Ann Arbor, Michigan

Elbow pain is a frequent clinical complaint in baseball pitchers. The possible etiology of this discomfort is varied and includes epiphyseal injuries, medial collateral ligament strains, osteochondritis, epicondylitis, and ulnar neuropathy ${ }^{2,6,12}$ Conservative measures comprise the initial treatment regimens used for these diagnoses. Surgical intervention is occasionally required, and should be directed toward a specific region of suspected pathology. A recent case of ulnar neuritis in the throwing arm of a baseball pitcher emphasized the need for an accurate physical examination and knowledge of surgical anatomy.

\section{CASE REPORT}

A 20-year-old right-handed male presented with a 12 month history of right elbow pain. He was a pitcher on the baseball team of a large midwestern university. Although he relied primarily on his fast ball, the pain was first noted following a vigorous practice session in which multiple breaking pitches were thrown. The sharp discomfort was located along the medial aspect of his proximal forearm and was associated with distal dysesthesias in the ulnar nerve distribution. The initial presentation was very specific in location and quite severe in intensity. Rest and immobilization relieved the symptoms, but resumption of pitching activities continued to precipitate his complaints.

Physical examination revealed normal sensation of the hand and forearm. No atrophy was noted and symmetric range of motion of all joints was appreciated. No tenderness at the medial epicondyle was detected, and resisted wrist flexion did not cause discomfort. The patient was not tender over his ulnar nerve in the cubital tunnel, but had pain when palpating this nerve just distal to the elbow. This

\footnotetext{
* Address correspondence and reprint requests to: F. M. Hankin, MD, 2912L Taubman Health Care Center, Box 0328, Section of Orthopaedic Surgery, University Hospital, Ann Arbor, Ml 48109.
}

tenderness was similar to his throwing complaints and was felt to represent entrapment of the ulnar nerve within the flexor carpi ulnaris (FCU) muscle. Plain radiographs and elbow arthrography were unremarkable. Electromyoneurography studies were also normal. Local anesthetic injections into the medial epicondylar region did not alleviate the symptoms. Cast immobilization ameliorated the discomfort but did not provide long-term relief from the pain once throwing activities were resumed.

The patient underwent surgical exploration and decompression of his ulnar nerve. The superficial aponeurosis connecting the two heads of the FCU was hypertrophic and was released. The patient's area of maximal clinical tenderness corresponded to the area where the ulnar nerve passed beneath the deep aponeurosis of the FCU (Fig. 1). These deep fascial fibers were similarly released and a mild concave impression on the inflamed ulnar nerve was noted at this

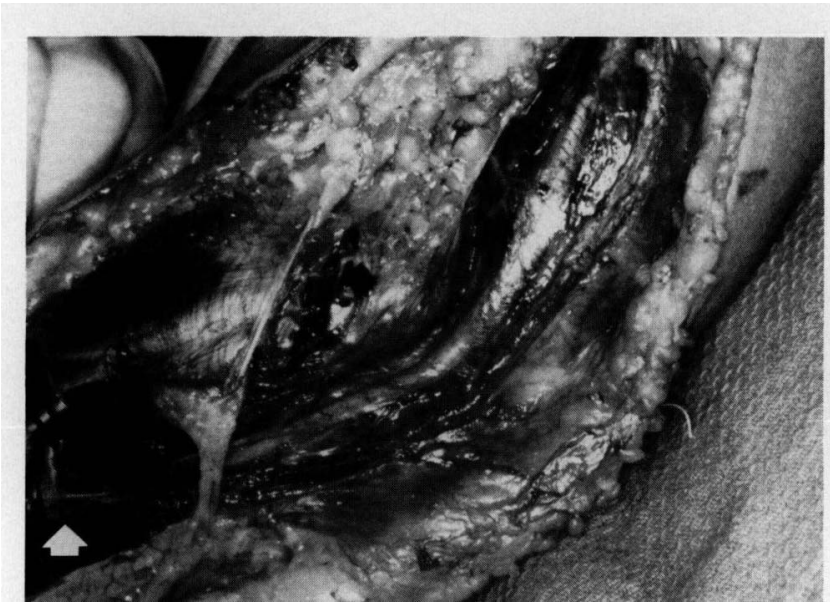

Figure 1. Superficial aponeurosis between the two heads of the FCU has been released. The deep aponeurosis overlying and compressing the ulnar nerve is evident (arrow). 


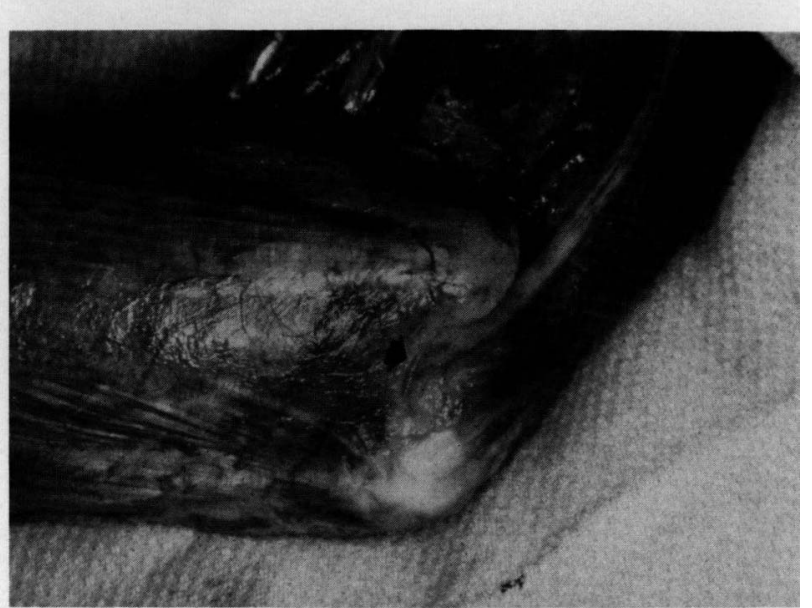

Figure 2. Cadaver specimen demonstrates the superficial fibrous arcade connecting the two heads of the FCU (arrow). The ulnar nerve passes beneath this structure.

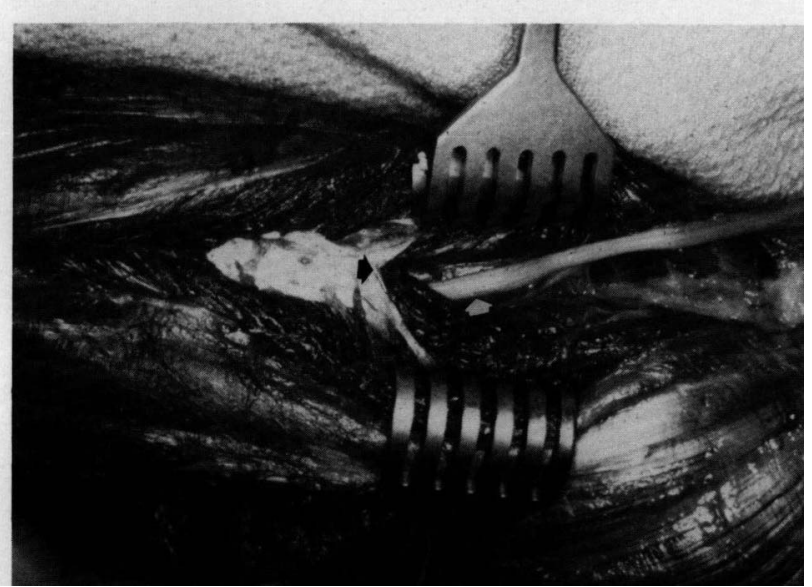

Figure 3. The deep aponeurosis (dark arrow) of the FCU in this cadaver specimen forms a potential site of extrinsic compression on the underlying ulnar nerve (white arrow).

location. The ulnar nerve was then decompressed proximally in the cubital tunnel where it had a normal appearance. Clinical subluxation of the ulnar nerve in the tunnel was not noted with flexion and extension of the elbow.

The patient was immobilized at $60^{\circ}$ for 2 weeks and then begun on a splinting program which permitted motion between $0^{\circ}$ and $60^{\circ}$. Wrist motion and forearm rotation were integrated into the rehabilitation program at 4 weeks and full elbow flexion at 6 weeks postoperatively. Resistive exercises were initiated at 8 weeks and light throwing at 3 months. Full throwing activities at 4 months were without pain or paresthesias.

\section{DISCUSSION}

The FCU contributes to wrist flexion, ulnar deviation of the wrist, forearm supination, and elbow flexion. The double origin of this muscle consists of one head from the medial epicondyle of the humerus and the second from the medial and posterior borders of the ulna. A superficial aponeurosis connects the two heads of origin (Fig. 2). The deep aponeurosis of FCU is located in the proximal forearm and provides a common fascial origin for FCU, flexor digitorum superficialis, and profundus muscles (Fig. 3). The ulnar nerve enters the forearm after passing between the two FCU heads of origin and beneath the fascial arcades. Compressive neuropathy of the ulnar nerve as it passes through the FCU has been reported, ${ }^{1,4,5,7}$ Recent publications have implicated the deep aponeurosis connecting the ulnar and humeral FCU origins, as noted in our patient, in the pathogenesis of the extrinsic entrapment. ${ }^{3,8,9}$ Decompression or transposition of the ulnar nerve without release of these FCU fascial arcades would therefore be an incomplete procedure and could potentially aggravate extrinsic compression on the nerve by these structures.

Electrodiagnostic examinations of the ulnar nerve at the elbow are frequently equivocal. Clinical signs of ulnar neuropathy include tenderness along the course of the nerve, pain with flexion of the elbow, weakness of ulnar innervated muscles, and respective sensory abnormalities. Treatment intervention includes rest, antiinflammatory medication, activity modification, splinting, and occasionally surgical decompression and transposition. ${ }^{10,15}$

The combination of elbow extension, ulnar deviation of the wrist, and forearm supination is needed for throwing a breaking pitch. These maneuvers directly involve contraction of the FCU. The normal proximal fascial arcades of the FCU may also become hypertrophic in baseball pitchers due to the repetitive tensile stresses. These proximal forearm fascial structures may then produce static and dynamic entrapment neuropathy of the ulnar nerve. The normal valgus strain applied to the elbow during throwing maneuvers also serves to stretch the medially situated ulnar nerve.

Decompression or anterior transposition of the ulnar nerve for symptoms of ulnar neuritis in competitive baseball pitchers is frequently unpredictable and ungratifying. Too often, the patient is unable to return to the throwing sport. If decompression and/or transposition surgery for the ulnar nerve at the elbow is to be successful, a thorough knowledge of the local anatomy is required.

\section{REFERENCES}

1. Adelaar RS, Foster WC, McDowell C: The treatment of the cubital tunnel syndrome. J Hand Surg 9: 90-95, 1984

2. Albright JA, Jokl P, Shaw R, et al: Clinical study of baseball pitchers: Correlation of injury to the throwing arm with method of delivery. $A m J$ Sports Med 6: 15-21, 1978

3. Amadio PC, Beckenbaugh RD: Entrapment of the ulnar nerve by the deep flexor-pronator aponeurosis. J Hand Surg 11A: 83-87, 1986

4. Apfelberg DB, Larson SJ: Dynamic anatomy of the ulnar nerve at the elbow. Plast Reconstr Surg 51: 76-81, 1973

5. Broudy AS, Leffert RD, Smith RJ: Technical problems with ulnar nerve transposition at the elbow. Findings and results of reoperation. $J$ Hand Surg 3: 85-89, 1978

6. Clarke NM, Blakemore ME, Thompson AG: Osteochondritis of the trochlear epiphysis. J Pediatr Orthop 3: 601-604, 1983

7. Foster RJ, Edshage S: Factors related to the outcome of surgically managed compressive ulnar neuropathy at the elbow level. $J$ Hand Surg 6: $181-192,1981$ 
8. Hankin FM, Smith PA, Kling TF, et al: Ulnar nerve palsy following rotational osteotomy of congenital radio-ulnar synostosis. $J$ Pediatr Orthop, in press, 1986

9. Inserra $S$, Spinner M: An anatomic factor significant in the transposition of the ulnar nerve. J Hand Surg 11A: 80-82, 1986

10. Jones RE, Gauntt $\mathrm{C}$ : Medial epicondylectomy for ulnar nerve compression syndrome at the elbow. Clin Orthop 139: 174-178, 1979

11. Leffert RD: Anterior submuscular transposition of the ulnar nerves by the Learmonth techique. J Hand Surg 7: 147-155, 1982
12. Pappas AM: Elbow problems associated with baseball during childhood and adolescence. Clin Orthop 164: 30-41, 1982

13. Thomsen PB: Compression neuritis of the uinar nerve treated with simple decompression. Acta Orthop Scand 48: 391-393, 1977

14. Wadsworth TG: The external compression syndrome of the ulnar nerve at the cubital tunnel. Clin Orthop 124: 189-204, 1977

15. Wilson $\mathrm{DH}$, Krout $\mathrm{R}$ : Surgery of ulnar neuropathy at the elbow: 16 cases treated by decompression without transposition; technical note. J Neurosurg 38: $780-785,1973$ 